\title{
GENEALOGIA DO BIOPODER
}

Luiz Alberto Moreira Martins

Carlos Augusto Peixoto Junior

Pontifícia Universidade Católica do Rio de Janeiro, Rio de Janeiro, Brasil

RESUMO: O objetivo do presente artigo, é rastrear os elementos, as questões e problematizações que possibilitaram à Michel Foucault, a elaboração dos conceitos de biopoder, biopolítica, governamentalidade e segurança. Pretendemos neste trabalho, investigar a genealogia do biopoder e da biopolítica, buscando retraçar nas reflexões de Foucault, em torno da medicalização da sociedade e da extensão do poder médico, no período 1974-1976, especialmente nas conferências da UERJ, todo um questionamento que preparava a emergência das noções de biopoder e biopolítica, tal como foram propostas por ele em 1976. Podemos supor que a articulação feita por Foucault, entre a medicalização da sociedade e o governo da vida foi uma das condições que tornaram possível a emergência da hipótese do biopoder.

PALAVRAS-CHAVE: biopoder; biopolítica; governamentalidade; segurança; população.

\section{GENEALOGY OF BIOPOWER}

ABSTRACT: The objective of the present paper is to trace the elements, the questions and problematizations that rendered possible to Foucault the elaboration of the concepts of biopower, biopolitics, governmentality and security. In this work we intend to investigate the genealogy of biopower and biopolitics, seeking to retrace in Foucault's reflections around the medicalization of society and the extension of medical power - in the period 1974-1976, especially in the lectures at UERJ - the questioning that prepared the emergence of the notions of biopower and biopolitics, as proposed by him in 1976. We can suppose that the articulation made by Foucault between the medicalization of society and the government of life was one of the conditions that rendered possible the emergence of the hypothesis of biopower.

KEYWORDS: biopower, biopolitics, governmentality, security, population.

O objetivo do presente artigo é o de rastrear os elementos e articulações que possibilitaram a Michel Foucault a elaboração dos conceitos de biopoder, biopolítica, governamentalidade e segurança. Pretendemos fazer uma genealogia do biopoder e da biopolítica, buscando retraçar os caminhos que tornaram possível a construção dessas noções.

As questões e problematizações em torno das noções de biopoder, biopolítica e população já estavam presentes no pensamento de Foucault, ainda que de forma germinal, pelo menos desde 1974; podemos constatar isso nas três conferências do Rio de Janeiro, realizadas no Instituto de Medicina Social da Universidade do Estado do Rio de Janeiro (UERJ), em outubro daquele ano, e mais tarde, em 1976, no artigo "La Politique de la santé au XVIII siècle" (Foucault, 1976b), trabalho que foi reeditado com modificações e acréscimos em 1979 (Foucault, 1979/2001d).

As conferências do Rio de Janeiro tinham como tema geral o nascimento da medicina social, no contexto da medicalização da sociedade, o que, segundo Foucault, teve início no século XVIII, e evidenciam o papel central desse tema na elaboração posterior dos conceitos de biopoder e biopolítica, articulados com a noção de população. Essas conferências fazem parte das investigações apresentadas por Foucault, no ano seguinte, no curso Os anormais (Foucault, 1975/2002). $\mathrm{Na}$ ocasião, a disciplina constituía ainda a grade de investigação privilegiada por ele em sua abordagem sobre o poder, tanto que um dos objetos de análise era uma instituição disciplinar: o hospital. No entanto, já é possível encontrar nesse momento de sua produção todo um questionamento a respeito das relações da medicina com a população, com o meio urbano e com a doença como fenômeno natural, marcado por regularidades.

As relações entre a medicina e a economia política, a estatização da medicina e o governo da vida também estão presentes nessas conferências, temas que serão retomados nos cursos Sécurité, Territoire, Population, em 1978, e La Naissance de la biopolitique, em 1979.

Há, enfim, nessas conferências, vários elementos que se articulam com a emergência dos conceitos de biopoder, biopolítica das populações, governamentalidade e segurança. 
Na primeira conferência, Crise de la médicine ou crise de l'antimédicine? (Foucault, 1976/2001a), Foucault aborda um tema que será retomado mais tarde, em outros trabalhos: a relação entre o pastorato ${ }^{1}$ cristão e o governo dos homens. O cristianismo, desde o Império romano, fez da alma um dos objetivos da intervenção do "Estado", já que se propôs a cuidar das almas e salvá-las. Se até o século XVIII as teocracias europeias incluíam entre suas tarefas a salvação das almas, a partir daí, começa a ser preparado e construído o regime sob o qual vivemos hoje, uma "somatocracia". "Nós vivemos sob um regime para o qual uma das finalidades da intervenção estatal é o cuidado do corpo, a saúde corporal, a relação entre doença e saúde, etc." (Foucault, 1976/2001a, p. 43).

O poder dirigido para a salvação das almas se transformou e, com o enfraquecimento da instituição eclesiástica, ele se desdobrou e se estendeu para o Estado em sua forma moderna. A salvação espiritual assume então uma forma terrestre, se infiltra no corpo social, e passa a ter como objetivos a saúde e o bem-estar da população (Foucault, 1984, Dreyfus \& Rabinow, 1984, p. 306). Se até o século XVIII a medicina se ocupava do doente e das doenças, houve depois disso uma progressiva medicalização do Estado, das cidades e da população. A vida em seu conjunto passa a ser objeto de preocupação do Estado, por meio da intervenção médica. Essas considerações se situam na raiz do que mais tarde será o conceito de biopoder. É o que Foucault, nesta primeira conferência, denominou bio-história, ou seja, um novo regime de historicidade, de relações de interferência entre os movimentos da vida e os processos históricos, que se define enfim, pela entrada da vida na história, no campo das técnicas políticas. "O médico e o biólogo não trabalham mais, doravante, no nível do indivíduo e de sua descendência, mas começam a fazê-lo no nível da própria vida e de seus acontecimentos fundamentais" (Foucault, 1976/2001a, p. 48).

A medicina passa a intervir num campo mais amplo da existência do indivíduo e da população, apoiada pela integração do seu saber a estratégias emergentes de governo, na segunda metade do século XVIII. "Desde o século XVIII, a medicina não cessou de se ocupar daquilo que não a concerne, quer dizer, daquilo que não se liga aos diferentes aspectos dos doentes e das doenças" (Foucault, 1976/2001a, p. 50).

Foucault atribui a medicalização da medicina, da sociedade e da população a quatro processos ligados à expansão do domínio do saber médico, em especial na segunda metade do século XVIII, e que caracterizam a medicina deste período. Os quatro processos, que serão abordados nos tópicos seguintes, são: o aparecimento da autoridade médico-política e a instauração da medicina de Estado e da polícia médica; a ampliação dos domínios da medicina para além dos doentes e da doença, com a constituição da medicina urbana; ${ }^{2}$ a medicalização do hospital, quer dizer, sua transformação em instrumento terapêutico; e, por fim, a constituição de "mecanismos de administração médica: registro de dados, estabelecimento e comparação de estatísticas, etc." (Foucault, 1976/2001a, p. 50).

\section{Ciência do Estado e Polícia Médica}

Primeiramente, no que tange ao surgimento de uma autoridade médica - autoridade social e política, que decide sobre a cidade, sobre uma instituição ou sobre as regras que concernem à saúde e à doença, etc. - vale assinalar que estamos falando de uma medicina de Estado, a Staatzmedizin dos alemães, sustentada pela polícia médica, a qual abordaremos adiante. A medicina do Estado teria surgido na Alemanha, no início do século XVIII e estava articulada com a "estatística" como ciência do Estado, Staatswissenshaft. Essa ciência do Estado implica admitir um saber do Estado, quanto aos seus recursos naturais, condições de vida e qualidade da saúde da população (com suas taxas de natalidade e mortalidade), e também no que se refere ao funcionamento da máquina política estatal (Foucault, 1977/2001b, p. 210).

E implica ainda os métodos pelos quais o Estado produz e acumula conhecimentos que possibilitam o seu funcionamento. Foucault aborda aqui mais um tema que será retomado em Sécurité, Territoire, Population e em La Naissance de la Biopolitique, a constituição, no século XVII, da polícia e de uma ciência do Estado, de uma reflexão calculada sobre o Estado.

Essa ciência do Estado começa a se forjar no século XVII, a partir das práticas derivadas do cameralismo e do mercantilismo, não apenas enquanto doutrinas econômicas, mas como modos de governar, como práticas de governo que visavam a "regular as correntes monetárias internacionais, os fluxos correspondentes de mercadorias e a atividade produtiva da população. A política mercantilista assentava-se essencialmente sobre o crescimento da produção e da população ativa" (Foucault, 1977/2001b, p. 212). É nesse contexto que a saúde da população torna-se objeto de preocupação e avaliação para os Estados emergentes da Europa. Até o período mercantilista, a população aparecia apenas como um dos elementos que refletiam a potência do soberano, juntamente com a extensão do seu território e a importância de suas riquezas. Com o mercantilismo, a partir do século XVII, a população aparece como o elemento fundamental, o princípio mesmo, da riqueza e da potência do Estado. Afinal, a população é a força que produz essas riquezas. Ainda que os mercantilistas tenham sido os primeiros a considerar a população essencialmente enquanto força produtiva, ela na verdade 
só pôde ser considerada nesses termos porque estava submetida a um regime disciplinar e enquadrada por um aparelho regulamentador. Quer dizer, isso só foi possível porque essa população acabou sendo "efetivamente adestrada, repartida, distribuída, fixada segundo os mecanismos disciplinares. População, princípio de riqueza, força produtiva, enquadramento disciplinar: tudo isso forma uma unidade no interior do pensamento, do projeto e da prática política dos mercantilistas." (Foucault, 2004b, p. 71)

Assim, embora os mercantilistas e cameralistas considerassem a população, submetida aos dispositivos disciplinares, o fundamento da riqueza do Estado, ela era ainda pensada em termos jurídicos, como "a coleção de súditos de um soberano" (Foucault, 2004b, p. 72). O que estava em jogo nessas doutrinas e nessa forma de racionalização do exercício do poder era o crescimento da potência e da riqueza do Estado. Segundo Foucault, o sujeito/objeto população não tinha, ainda, com o mercantilismo e o cameralismo, adquirido sua autonomia, nem tampouco se emancipado do poder do Estado.

No entanto, ainda não havia modalidades de intervenção para melhorar a saúde da população. As formas de intervenção organizadas e refletidas em torno da melhoria da saúde pública surgem na Alemanha com o conceito de Medizinischepolizei, ou polícia médica.

Foucault atribui a introdução da polícia médica a um autor alemão, Johann Peter Frank, o qual publicou em cinco volumes, entre 1779 e 1790 , o que seria o primeiro tratado de saúde pública, cujas propostas iam muito além do simples levantamento das taxas de natalidade e mortalidade. $\mathrm{O}$ estudo englobava, mais propriamente, o projeto de saúde pública de Frank enquanto "organização de um saber médico do Estado, da normalização da profissão médica, da subordinação dos médicos a uma administração geral e, por fim, da integração dos médicos numa organização médica do Estado" (Foucault, 1977/2001b, p. 214). Oito anos depois, em outubro de 1982, num dos seminários na Universidade de Vermont, intitulado "La technologie politique des individus" (Foucault, 1988/2001e, pp. 1.632-1.647), Foucault retoma esse mesmo autor, já no contexto de uma reflexão sobre o biopoder e o governo político das populações, a obra de Frank é o primeiro grande programa sistemático de saúde pública para o Estado moderno. Ele indica com um luxo de detalhes o que deve fazer uma administração para garantir uma revitalização geral, moradias decentes, a saúde pública, sem esquecer as instituições médicas necessárias à boa saúde da população, enfim, para proteger a vida dos indivíduos. (Foucault, 1988/2001e, p. 1.634)

Nessas condições, o Estado passa a se encarregar da vida individual e coletiva, a vida torna-se então objeto de governo. Ora, essa polícia médica é elemento de um conjunto tecnológico mais amplo: a polícia. Foucault considera que essa tecnologia de poder começa a se desenvolver a partir do século XVII como o "conjunto de meios pelos quais pode-se fazer crescer as forças do Estado mantendo-o ao mesmo tempo em boa ordem" (Foucault, 2004b, p. 321). Para alcançar esse objetivo, o Estado deve conhecer suas forças, sua população, sua produção, suas riquezas, seu comércio, etc., o que implica um saber sobre o próprio Estado. Esse é o momento em que emerge um domínio específico de conhecimento: a estatística. "A estatística torna-se necessária pela polícia, mas ela torna-se igualmente possível pela polícia" (Foucault, 2004b, p. 323). A polícia, na medida em que torna possível a emergência desse campo de saber que é a estatística, constitui, ao mesmo tempo, o objeto desse campo, ou seja, a população. A noção de população, como objeto autônomo de reflexão política, vai ser elaborada, no século XVIII, por meio da intervenção do conjunto de práticas que constitui a polícia.

\section{A Medicina Urbana}

O segundo processo, ligado ao desenvolvimento da medicina social e da medicalização da sociedade, foi o nascimento da medicina urbana. Essa medicina surge com o desenvolvimento e as transformações das estruturas urbanas. As grandes cidades, ao mesmo tempo em que centralizavam as atividades comerciais, eram centros produtores. Além disso, o desenvolvimento das cidades e a indústria nascente também contribuíram para a formação de uma população operária e pobre. "O fato de que a cidade não era somente um lugar de mercado, mas também um lugar de produção, tornou obrigatório o recurso a mecanismos de regulação homogêneos e coerentes" (Foucault, 1977/2001b, p. 216).

Nesse contexto, Foucault aborda os exemplos que serão tratados no curso de 1975 , Os anormais: o sistema de exclusão da lepra e o sistema de quarentena da peste. No primeiro modelo, comum nas sociedades ocidentais desde a Idade Média, separavam-se, com rigor, os casos de lepra, excluindo-os do espaço comum, da cidade; o que se buscava com isso era uma purificação do meio urbano. No segundo modelo, utilizado no final do século XVII e início do XVIII para combater a peste, não se excluía, mas sim incluía. No caso da peste, o poder político da medicina dividia a cidade em setores e subsetores, todos os movimentos eram registrados, tudo e todos eram constantemente vigiados e controlados. "O momento da peste é o momento do policiamento exaustivo de uma população por um poder político, cujas ramificações capilares atingem sem cessar o próprio grão dos indivíduos, seu tempo, seu hábitat, sua localização, seu corpo" (Foucault, 1997/2005, p. 59). O modelo da quarentena da peste visava a "maximizar a saúde, a longevidade, a força dos indivíduos. Tratava-se 
no fundo de produzir uma população sadia" (Foucault, 1997/2005, p. 58).

O modelo da peste vem substituir a grande internação, o modelo do hospital geral como lugar dos excluídos. A introdução do modelo da peste marca a emergência das tecnologias positivas de poder, dos mecanismos disciplinares e de uma nova "arte de governar".

A medicina urbana e a higiene pública, na visão foucaultiana, seriam um prolongamento refinado do modelo da quarentena, mantendo, no entanto, seus procedimentos de vigilância e controle. Essa medicina teria se constituído em torno de alguns objetivos principais: analisar os lugares de acúmulo de restos e dejetos, no interior do espaço urbano, os quais poderiam ser focos de enfermidades e de epidemias; controlar a circulação, do ar, da água, dos alimentos e mercadorias; estudar a distribuição e organização dos elementos indispensáveis à vida no espaço da cidade, tais como fontes, esgotos, etc.

Todos esses objetivos se articulavam a saberes emergentes, que atribuíam a aspectos do meio, e às condições de vida da população e aos seus hábitos, a origem e a propagação de diversas enfermidades. A medicina urbana se constitui então muito mais como uma medicina dos elementos e das coisas, dos processos físico-químicos, muito mais do que uma medicina dos corpos. "Essa medicina das coisas esboçava já, sem que o termo todavia aparecesse, o conceito de meio ambiente que os naturalistas do fim do século XVIII, como Cuvier, iriam desenvolver" (Foucault, 1977/2001b, p. 222). Com a medicina urbana surge também a noção de salubridade, a qual remete aos elementos que constituem o estado do meio ambiente, e que podem então afetar a saúde dos indivíduos. A higiene pública se constitui como "técnica de controle e de modificação dos elementos do meio que podem favorecer esta saúde ou, ao contrário, prejudicá-la" (Foucault, 1977/2001b, p. 223). Foucault retomará essa temática do espaço urbano, dos problemas de circulação e do meio ambiente no curso Sécurité, Territoire, Population, não como prolongamento refinado da tecnologia disciplinar, mas no contexto da emergência de uma nova tecnologia do poder, que é a dos dispositivos de segurança, tendo como pano de fundo a governamentalidade.

\section{O Meio Ambiente e a Naturalidade dos Fenômenos}

O terceiro processo, mais familiar, é abordado por Foucault na terceira conferência, "L'incorporation de l'hôpital dans la technologie moderne" (Foucault, 1978/2001c, pp. 508-521). Nela, o autor descreve a transformação do hospital geral, no início do século
XVIII - ele funcionava como instituição de exclusão e de assistência ao mesmo tempo, e ali se misturavam loucos, doentes, prostitutas, enfim, toda sorte de excluídos - em instrumento terapêutico e de cura. Está em jogo, segundo ele, todo um processo de medicalização do hospital, o que se torna possível graças à "introdução dos mecanismos disciplinares no espaço desordenado do hospital" (Foucault, 1978/2001c, p. 517) e à extensão da prática da medicina, que se volta agora para os problemas do ambiente, "na medida em que a doença passa a ser considerada como um fenômeno natural, que obedece a leis naturais" (Foucault, 1978/2001c, p. 517).

O fato de a doença passar a ser considerada fenômeno natural introduz duas questões importantes: primeiro, a noção de meio, ambiente ou meio ambiente, e, em seguida, a noção de naturalidade atribuída a certos fenômenos. Vejamos a noção de meio ambiente, para depois nos determos sobre a concepção da naturalidade dos fenômenos. A noção de meio, proveniente da física newtoniana, ainda não estava presente no início do século XVIII. Ela só vai aparecer na biologia, de forma indireta, com Lamarck, ${ }^{3}$ e depois com Cuvier e Darwin.

Lamarck fala sempre de meios, no plural, e entende, com isso, estritamente os fluidos como a água, o ar e a luz. Quando Lamarck quer designar o conjunto das ações que se exercem do exterior sobre o vivente, quer dizer, o que nós hoje chamamos de meio, ele não diz jamais o meio, mas sempre "circunstâncias influentes". (Canguilhem, 1975, p. 131)

A referência epistemológica de inteligibilidade das doenças nessa época ainda era o sistema classificatório de Lineu, a história natural. Somente com as transformações que tiveram lugar a partir da segunda metade do século XVIII e início do XIX, pôde haver uma passagem do sistema classificatório para a análise interna do organismo e, depois, "do organismo na sua coerência anátomo-funcional às relações constitutivas ou reguladoras desse organismo com o meio de vida" (Foucault, 2004b, p. 79). Como se vê, a noção de meio é contemporânea da emergência do conceito de organismo e da passagem da história natural para a biologia. ${ }^{4}$ Quanto a essa última ideia, Foucault afirma, em Sécurité, Territoire, Population, que "é a problematização, então, da população no interior dessa análise dos seres vivos que permitiu passar da história natural à biologia" (Foucault, 2004b, p. 80).

Se a noção de meio ainda não havia sido formulada de modo explícito pelos saberes médico e urbanístico da primeira metade do século XVIII, ela já se fazia presente, ainda que não enunciada, nas práticas emergentes da medicina urbana, dos arquitetos e dos primeiros urbanistas. Se em termos nocionais mais específicos ela não existia propriamente, "eu diria que o esquema técnico dessa noção de meio, a espécie/tipo - como di- 
zer? - de estrutura pragmática que a desenha de antemão está presente na maneira pela qual os urbanistas tentam pensar e modificar o espaço urbano" (Foucault, 2004b, p. 22). Além disso, ela ainda estaria presente na extensão do campo de intervenção médica para o espaço urbano. Esse tipo de medicina não visa à doença em si, mas tudo àquilo que, no ambiente, pode favorecer ou dificultar o surgimento da doença: o ar, a água, a alimentação, a higiene, a temperatura, a umidade, etc.

A segunda questão importante diz respeito à concepção da naturalidade de um fenômeno. Ela não é exclusiva do pensamento médico, no fim do século XVIII, uma vez que já estava presente na teoria dos fisiocratas. Nessa teoria, toda a análise econômica está centrada na ideia da naturalidade dos processos envolvidos, nas interferências climáticas na produção agrícola, na relação entre escassez e elevação dos preços, etc. É quando a multiplicidade do humano passa a ser pensada como dependente da interação de uma série de variáveis - tais como o clima, o seu ambiente material, a circulação de mercadorias e riquezas e os hábitos - que ela pode emergir como população, como sendo ela própria também um fenômeno natural, que não é inteiramente controlável, mas ainda assim permeável às técnicas de intervenção. Quando a população se constitui como um elemento a ser considerado, no campo da teoria e da prática econômica abre-se, na visão de Foucault, "um domínio de saber novo que é a economia política" (Foucault, 2004b, p. 79). A introdução da população na reflexão econômica possibilita a passagem da análise das riquezas para a economia política. ${ }^{5}$ Enfim, é essa concepção de naturalidade - de uma aleatoriedade inevitável de um conjunto de fenômenos, ligados à vida humana, a qual se desenvolveu no fim do século XVIII - que vai possibilitar a emergência de uma nova racionalidade governamental, de um novo dispositivo de poder que será por ele descrito em 1978, como dispositivo de segurança ou de regulação: "A economia política pôde se constituir a partir do momento onde, entre os diferentes elementos da riqueza, apareceu um novo sujeito, que era a população" (Foucault, 2004b, p. 109). Trata-se, então, de uma tecnologia governamental, uma arte de menos governar, que tem como condição de possibilidade a percepção e o reconhecimento da naturalidade de certo número de fenômenos indissociáveis uns dos outros, fenômenos econômicos, demográficos, etc.

No final dessa terceira conferência, Foucault introduz a ideia de poder médico ao mesmo tempo individualizante e totalizante, que intervém sobre cada um e sobre a população, ideia constitutiva do conceito de biopoder.

Graças à tecnologia hospitalar, o indivíduo e a população se apresentam simultaneamente como objetos de saber e da intervenção médica. A medicina que se forma no curso do século XVIII é ao mesmo tempo uma medicina do indivíduo e da população. (Foucault, 1978/2001c, p. 521).

Por fim, o quarto processo ao qual Foucault atribui a medicalização da sociedade é a articulação da medicina com outros saberes, sobretudo a estatística. Tal articulação vai levar à constituição de mecanismos de registro e comparação de dados sobre a saúde, a doença e a qualidade da população. A partir das transformações que conduziram a uma medicalização da sociedade, poderíamos concluir que a medicina, porque atua cada vez mais "para além de suas fronteiras tradicionais definidas pelo doente e pelas doenças, começa a não ter mais domínio que lhe seja exterior" (Foucault, 1976/2001a, p. 51).

$\mathrm{Na}$ segunda conferência, "La Naissance de la Médicine Social", Foucault define a "bio-história" como efeito de uma intervenção médica maciça na história da espécie humana. A história do homem enquanto espécie é afetada, a partir do século XVIII, pela medicalização cada vez mais intensa das condutas, do comportamento e da existência. A medicina social se fundamenta numa tecnologia que atua sobre o corpo social. Na análise histórica que Foucault empreende sobre a medicalização da sociedade, constatamos que já estão presentes os elementos que serão retomados alguns anos mais tarde, e que envolvem as noções de biopoder, biopolítica, governamentalidade, população e segurança. Apesar de a dimensão coletiva da população já estar presente nessas conferências, a abordagem de Foucault permanecia centrada na dimensão do corpo individual, ou seja, na dimensão disciplinar.

No artigo citado no início do artigo, "La politique de la santé au XVIII siècle", de 1976, Foucault já aborda a questão da população de modo mais específico, não apenas como força de trabalho num enquadramento disciplinar, mas como um personagem político novo, que emerge no século XVIII. Segundo Foucault, a grande expansão demográfica ocorrida na Europa, ao longo do século XVIII, tinha que ser coordenada e integrada ao desenvolvimento do aparelho de produção, "a urgência de controlá-la (a expansão demográfica) por mecanismos de poder mais adequados e mais densos, fazem aparecer a 'população'... Se esboça o projeto de uma tecnologia da população." (Foucault, 1976b, p. 14).

A questão da arte de governar e sua relação com a política médica, que então emergia, também é estudada neste artigo. "O médico torna-se o grande conselheiro e o grande perito senão na arte de governar, pelo menos na de observar, de corrigir, de aprimorar o corpo social

e de mantê-lo num estado permanente de saúde" (Foucault, 1976b, p. 14). Nesse mesmo artigo, modificado e reeditado em 1979, Foucault volta a tratar da importância da polícia como um dos elementos que tornou possível a formação de uma política de saúde no 
século XVIII, a polícia era então uma técnica de gestão do "corpo social" na sua materialidade, e no centro dessa materialidade estava a população, entendida como "um conjunto de indivíduos tendo entre eles relações de coexistência e constituindo por essa razão uma realidade específica" (Foucault, 1979/2001d, p. 730). Temos, aqui, a noção de população como objeto autônomo, com suas variáveis e regularidades próprias, que podem ser modificadas por meio de intervenções específicas.

\section{Conclusão}

Em 1976, já estavam bastante avançadas as investigações de Foucault sobre uma concepção do poder diferente daquela da filosofia e da teoria política tradicionais, quer dizer, dos filósofos contratualistas dos séculos XVII e XVIII e do pensamento marxista. As disciplinas e o poder normalizador foram objetos de extensa análise nos cursos do Collège de France do período 1971-1975 e especialmente em Vigiar e punir. Além disso, o projeto de uma analítica do poder construído nos cursos que acabamos de mencionar foi, pela primeira

vez, apresentado em detalhes no curso de 1976, Em defesa da sociedade e no primeiro volume da História da sexualidade, A vontade de saber, publicado no mesmo ano.

É nestes dois trabalhos de 1976 que a noção de biopoder $^{6}$ é apresentada como hipótese, ao lado de uma série de outras noções, como a de biopolítica, a de população e segurança. Portanto, é a partir desses dois trabalhos que Foucault introduz uma nova direção e produz um deslocamento de perspectiva em sua teoria, que faz com que as relações entre a dimensão microfísica ou individualizante do poder e a dimensão macrofísica ou totalizadora comecem a aparecer com mais clareza.

O poder disciplinar - ou a anatomopolítica do corpo humano - passa então a ser considerado por Foucault como uma das dimensões do biopoder. Integrando a tecnologia disciplinar no domínio mais amplo do biopoder, ao lado da biopolítica, dos mecanismos de segurança e dos dispositivos de regulação das populações, Foucault indica uma ampliação do domínio a ser investigado, mas não o explora ainda.

Os mecanismos disciplinares se integram, então, aos mecanismos de segurança e à biopolítica, numa perspectiva mais ampla que é a do poder sobre a vida, do biopoder. É na articulação da anatomopolítica dos corpos (que caracteriza os mecanismos disciplinares) com a biopolítica das populações (enquanto mecanismos de regulação e segurança) que teriam se produzido esse poder e esse saber sobre a vida, o investimento maciço sobre a vida e seus fenômenos, a partir de uma tecnologia refletida e calculada e da introdução da população como objeto de intervenção política, de gestão e de governo.
Se em Vigiar e punir Foucault analisou em minúcias a constituição e o funcionamento das disciplinas ou a anatomopolítica do corpo, que constituía o primeiro polo do biopoder, é em $A$ vontade de saber e na última aula do curso de 1976 que o segundo polo do biopoder, ou seja, o governo e o controle da vida enquanto biopolítica da população, surge como a outra face do poder sobre a vida. Foucault situa a constituição desse segundo polo, a biopolítica, em um momento posterior ao do primeiro, por volta de meados do século XVIII.

O que aparece, aí, é uma outra tecnologia de poder, não disciplinar. Ela não vem substituir ou tomar o lugar da técnica disciplinar, tampouco mantém com ela uma relação de conflito. Há, na realidade, entre a anatomopolítica e a biopolítica, sobreposição, interpenetração, enfim, uma espécie de complementaridade funcional (Artières \& Potte-Bonneville, 2007, p. 360). A tecnologia biopolítica encontra suporte na tecnologia disciplinar, ela a integra e modifica, enfim, se apoia nos mecanismos da disciplina para se instaurar ${ }^{7}$. A tecnologia biopolítica não tem como objeto e objetivo o corpo individual. Seu objeto se situa em outra escala: é uma tecnologia que vai se dirigir, se aplicar ao homem enquanto ser vivo, espécie, ou seja, população. Se a disciplina é individualizante e penetra o corpo em seus detalhes, a biopolítica focaliza a massa humana: o que interessa são os processos de conjunto, suas modulações e as variáveis que os afetam.

Para resumir, "essa tecnologia de poder, essa biopolítica, vai implantar mecanismos que tem certo número de funções muito diferentes das funções que eram as dos mecanismos disciplinares" (Foucault, 1997/2005, p. 293). Apesar disso, a disciplina e a biopolítica se encontram em seus objetivos; por mais diversos que sejam seus mecanismos, técnicas e modos de exercício, elas se sobrepõem e se completam, na medida em que visam a otimizar, maximizar e extrair a vida e as forças que a vida pode gerar, tanto no plano individual como no do conjunto vivente.

Resta-nos ainda comentar brevemente as vicissitudes das noções de biopoder e biopolítica na sequência dos trabalhos de Michel Foucault. O que encontramos nos cursos Sécurité, Territoire, Population, e La Naissance de la Biopolitique é uma grande operação de deslocamento. O que se esperava deles enquanto continuidade dos trabalhos de 1976 (Em defesa da sociedade e $A$ vontade de saber) é que tivessem como objeto a gênese do biopoder e o nascimento da biopolítica. Nas investigações de Foucault, a noção de biopolítica está constantemente presente como um programa de trabalho, como pano de fundo. Ela foi anunciada no início de Sécurité, Territoire, Population e proposta outra vez no título de La Naissance de la Biopolitique, mas é também uma noção sempre prometida e adiada, deixada para 
mais tarde. Mesmo não encontrando nesses cursos o que realmente se refere ao nascimento da biopolítica, foi, no entanto, a análise daquela que, permanecendo no horizonte das pesquisas de Foucault, tornou necessário o desvio para o estudo do liberalismo e possibilitou a elaboração de noções muito precisas, concretas, situáveis historicamente, tais como governamentalidade, segurança, conduta e liberdade.

Os dois cursos acima mencionados são, de alguma forma, a continuação um do outro, e poderiam ser englobados sob o título de "A história da governamentalidade", proposto pelo próprio Foucault no início da aula de $1^{\circ}$ de fevereiro de 1978 . Na ocasião, ele define a governamentalidade como um novo campo de pesquisa, envolvendo o estudo da racionalidade governamental ou a arte de governar.

Tendo como perspectiva metodológica a analítica do poder, Foucault abordou o tema do governo, no âmbito de seu exercício e de suas práticas e a racionalidade governamental, entendida como reflexão sobre a natureza e a atividade do governo. O que ele persegue é, então, a construção de uma história a partir de uma perspectiva diferente da história tradicional das ideias e das instituições políticas. A história da gênese do Estado moderno proposta por ele não se sustenta nas teorias jurídicas ou filosóficas da soberania, nem, tampouco, no ponto de vista das instituições, do poder público ou do jogo das forças econômicas. A grade de análise utilizada não exclui as outras, mas consolida a abertura do novo campo mencionado ou das tecnologias de governo.

Em Segurança, Território, População, Foucault analisa minuciosamente a constituição e a emergência da tecnologia de segurança, de seus mecanismos e a estreita correlação destes com a população. Foi tal correlação que conduziu Foucault, pouco a pouco, a introduzir e privilegiar a noção de governo. As elaborações foucaultianas em torno das noções de segurança e população se deslocam progressivamente da biopolítica para o que ele chamou de "governamentalidade". "A série: mecanismos de segurança - população - governo e a abertura do campo daquilo que chamamos a política, tudo isso, creio, constitui uma série que é preciso analisar." (Foucault, 2004b, p. 78).

Algumas razões parecem justificar tal deslocamento. Foucault assimila, em algumas passagens, as noções de biopolítica e governo, ou pelo menos atribui certo parentesco ou proximidade a tais noções: "Temos, de fato, um triângulo: soberania, disciplina e gestão governamental, uma gestão governamental cujo alvo principal é a população e cujos mecanismos essenciais são os dispositivos de segurança" (Foucault, 2004b, p. 111). Nada mudaria nessa afirmação se substituíssemos o conceito de gestão governamental pelo de biopolítica - são, aqui, sinônimos; ambos se caracterizam como "técnicas" que têm como objeto a população. A segunda razão que esclarece o deslocamento em foco se articula com as vicissitudes da noção de população no pensamento de Foucault. A noção de população na biopolítica está primordialmente referida e identificada a um conjunto de processos biológicos. A biopolítica “tende a tratar a 'população' como um conjunto de seres vivos e coexistentes, que apresentam traços biológicos e patológicos particulares" (Foucault, 2004b, p. 377). A população, enquanto objeto da biopolítica, vai ser uma noção a princípio construída no domínio da biologia e da medicina: o que estava em questão eram a espécie humana, a vida e as ameaças à vida. Foi a partir dessa perspectiva que Foucault analisou a emergência da polícia médica, da higiene pública e da medicina social no século XVIII; e foi também em torno dessas análises que se desenharam os primeiros contornos da biopolítica.

No entanto, é quando a população passa a incluir, ao lado da dimensão biológica, uma outra dimensão, que é a da "naturalidade" que a caracteriza, que ela pôde se tornar objeto de uma técnica de governo, de uma arte de governar. Se, por um lado, a população é apreendida como um conjunto de processos biológicos, por outro, ela se refere também a um conjunto de processos entendidos como "naturais". A naturalidade da população se refere a um conjunto de variáveis; assim, se do ponto de vista biológico, a população é, de certo modo, a espécie humana, do ponto de vista da naturalidade que a constitui, ela é o "público".

O público, noção capital no século XVIII, é a população tomada do lado de suas opiniões, de suas maneiras de fazer, de seus comportamentos, de seus hábitos, de seus temores, de seus preconceitos, de suas exigências, é sobre isso que se intervém pela educação, pelas campanhas, pelas convicções. A população é, então, tudo o que se estende desde o enraizamento biológico pela espécie até a superfície de captura oferecida pelo público. (Foucault, 2004b, p. 77).

Os dispositivos de segurança que operam na gestão governamental intervêm para modificar a população, modificando os elementos e as variáveis que a afetam, considerando e respeitando, no entanto, a naturalidade dessa população. É essa concepção de população, que se desenvolveu no quadro da economia política liberal, que permitiu a Foucault forjar o conceito de "governamentalidade", neologismo cunhado por ele na quarta aula de Sécurité, Territoire, Population. Essa noção de população o teria conduzido também a deslocar sua investigação da biopolítica para o domínio das artes de governar. A dimensão do "público", que inclui as maneiras de fazer, os comportamentos, os usos, permite então a abertura desse novo campo que é o da gestão governamental, entendida como condução de condutas. 
Podemos afirmar que em Sécurité, Territoire, Population, a governamentalidade tinha um sentido preciso, por vezes equivalente à biopolítica, e designava um regime de poder específico, que teria se instaurado no século XVIII, articulado com a questão do Estado. No entanto, é importante destacar aqui que

a identificação da governamentalidade com esse regime específico de exercício de poder é, na obra de Foucault uma etapa transitória. Se a oposição disciplina/ governo era, neste momento, suscetível de se sobrepor àquela prenunciada em $\mathrm{A}$ vontade de saber, entre anatomopolítica e biopolítica, os textos ulteriores concederão uma extensão sempre maior

à noção de "arte de governar", até abranger através dessa última o conjunto das relações de poder (Artières \& Potte-Bonneville, 2007, p. 374).

Podemos observar o deslocamento a que nos referimos, já no curso de 1979, La Naissance de la Biopolitique, onde a noção de governamentalidade aparece inteiramente transformada e ganha um sentido muito mais abrangente e abstrato. A redefinição da noção aparece na aula de 7 de março da 1979.

O próprio termo 'poder' apenas designa um [domínio] de relações que estão inteiramente abertas à análise, e o que propus chamar governamentalidade, quer dizer a maneira como se conduz a conduta dos homens, não é outra coisa senão uma proposição de grade de análise para essas relações de poder. (Foucault, 2004a, pp. 191-192).

O conceito deixa de se referir a um regime de poder específico e situado historicamente para se constituir como grade de análise das relações de poder, entendidas aqui como "condução de condutas" ou "arte de governar". Enfim, a noção de governamentalidade passa a englobar todo o campo estratégico das relações de poder, ou seja, a multiplicidade indefinida de técnicas e táticas destinadas a modificar e conduzir a conduta dos outros.

A extensão crescente do domínio de referência do conceito de governamentalidade descerrou um campo fecundo de novos temas e problematizações acerca das relações de poder e das resistências no mundo contemporâneo. Desses temas, apenas indicamos aqui dois que nos interessam especialmente e são objetos de nossas pesquisas atuais. $\mathrm{O}$ primeiro remete à politização do cotidiano, do ordinário e dos usos, temática que tem sido explorada por diversos autores como Le Blanc (2006), Artières \& Potte-Bonneville (2007), Bégout (2005), Feher (2005) e Revel (2006). O segundo refere-se ao conceito de risco, que é atualmente objeto de investigação de vários autores, entre os quais Hacking (2002), Ericson \& Doyle (2003), Vaz (2002). Esses pesquisadores têm observado que o conceito em questão adquiriu recentemente enorme relevância. Com certeza é uma noção cada vez mais infiltrada em nossas práticas cotidianas, funcionando como elemento implicado no processo de subjetivação, como fator determinante nas escolhas dos modos de viver e de cuidar de nós mesmos.

$\mathrm{O}$ que buscamos neste artigo foi retraçar nas reflexões de Foucault, em torno da medicalização da sociedade e da extensão do poder médico, no período 1974-1976, especialmente nas conferências da UERJ, todo um questionamento que preparava a emergência das noções de biopoder e biopolítica, tal como foram propostas por ele em 1976. Podemos supor que a articulação feita por Foucault entre a medicalização da sociedade e o governo da vida foi uma das condições que tornaram possível a emergência da hipótese do biopoder. Além disso, procuramos seguir as transformações e deslocamentos das noções em questão nos trabalhos desenvolvidos por Foucault nos anos seguintes, e a concomitante produção de conceitos derivados, conceitos ainda atuais e fecundos no que concerne à análise da atualidade.

\section{Notas}

1 Encontramos duas formas para traduzir pastorat: pastorado e pastorato. Apesar do uso mais frequente de pastorado, optamos pela forma pastorato ("pastorado ou pastorato, s.m. Dignidade ou função de pastor espiritual. Tempo durante o qual um pastor espiritual exerce essa função", segundo definição de dicionário).

2 A ampliação do campo da prática médica foi abordada, de forma mais exaustiva, na segunda conferência, "La Naissance de la médicine social" (In Dits et écrits II: 1976-1988, 2001b, pp. 207-228), sobre a constituição da medicina urbana, tema que será retomado no próximo tópico de nosso estudo.

3 Para uma análise mais profunda da noção de meio, ver Canguilhem (1975, pp. 129-154).

4 Tema investigado longamente por Foucault (1966), no capítulo "Classer" (pp. 137-176).

5 Tema desenvolvido por Foucault (1966), capítulo "Echanger" (pp. 177-185).

6 Os conceitos de biopoder e biopolítica são utilizados, aqui, tal como elaborados e definidos por Foucault nos trabalhos de 1976. O biopoder consiste na articulação de duas dimensões: uma individualizante, a anatomopolítica do corpo humano, e a outra totalizadora ou coletiva, a biopolítica da população (Foucault, 1976a, pp. 182-184).

7 Foucault assinala reiteradas vezes que a biopolítica não substitui outras modalidades de exercício do poder, por exemplo, em La volonté de savoir (Foucault, 1976a, p. 182-183), Em defesa da sociedade (Foucault, 2005, p. 299), Sécurité, territoire, population (Foucault, 2004b, p. 9-10).

\section{Referências Bibliográficas}

Artières, P. \& Potte-Bonneville, M. (2007). D'après Foucault: Gestes, luttes, programmes. Paris: Les Prairies Ordinaires.

Bégout, B. (2005). La découverte du quotidien. Paris: Allia.

Canguilhem, G. (1975). La connaissance de la vie. Paris: Librairie J. Vrin. 
Dreyfus, H. \& Rabinow, P. (1984). Michel Foucault: Un parcours philosophique. Paris: Gallimard.

Ericson, R. \& Doyle, A. (2003). Risk and morality. Toronto: University of Toronto Press.

Feher, M. (2005). Les interrègnes de Michel Foucault. In: M. Granjon (Org.), Penser avec Michel Foucault (pp. 251-299). Paris: Karthala.

Foucault, M. (1966). Les mots et les choses: Une archéologie des sciences humaines. Paris: Gallimard.

Foucault, M. (1975). Surveiller et punir: Naissance de la prision. Paris: Gallimard.

Foucault, M. (1976a). Histoire de la sexualité 1: La volonté de savoir. Paris: Gallimard.

Foucault, M. (1976b). La politique de la santé au XVIII siècle. In Les Machines à guérir. Aux origines de l'hôpital moderne; dossiers et documents (pp. 11-21). Paris: Institut de l'environnement.

Foucault, M. (1977). Vigiar e punir: nascimento da prisão. Petrópolis, RJ: Ed. Vozes, 1977.

Foucault, M. (1984). Deux essais sur le sujet et le pouvoir. In H. Dreyfus \& P. Rabinow (Orgs.), Michel Foucault: Un parcours philosophique (pp. 297-321). Paris: Gallimard.

Foucault, M. (2001a). Crise de la médicine ou crise de l'antimédicine? In Dits et écrits II, 1976-1988 (pp. 40-58). Paris: Gallimard. (Original publicado em 1976).

Foucault, M. (2001b). La naissance de la médicine sociale. In Dits et écrits II, 1976-1988 (pp. 207-228). Paris: Gallimard. (Original publicado em 1977).

Foucault, M. (2001c). L'incorporation de l'hôpital dans la technologie moderne. In Dits et écrits II, 1976-1988 (pp. 508-521). Paris: Gallimard. (Original publicado em 1978).

Foucault, M. (2001d). La politique de la santé au XVIII siècle. In Dits et écrits II, 1976-1988 (pp. 725-742). Paris: Gallimard. (Original publicado em 1979).

Foucault, M. (2001e). La technologie politique des individus. In Dits et écrits II, 1976-1988 (pp. 1632-1647). Paris: Gallimard. (Original publicado em 1988).

Foucault, M. (2001f). Dits et Écrits. Paris: Gallimard. (Original publicado em 1994).
Foucault, M. (2002). Os anormais. São Paulo: Martins Fontes. (Original publicado em 1975).

Foucault, M. (2004a). Naissance de la biopolitique. Paris: Seuil.

Foucault, M. (2004b). Sécurité, territoire, population. Paris: Seuil.

Foucault, M. (2005). Em defesa da sociedade. São Paulo: Martins Fontes. (Original publicado em 1997).

Hacking, I. (2002). Historical ontology. Cambridge, MA: Harvard University Press.

Le Blanc, G. (2006). La pensée Foucault. Paris: Ellipses.

Revel, J. (2006). Nas origens do biopolítico: de Vigiar e punir ao pensamento da atualidade. In J. Gondra. \& W. Kohan (Orgs.), Foucault 80 anos (pp. 51-62). Belo Horizonte: Autêntica.

Vaz, P. (2002). Um corpo com futuro. In A. Pacheco, G. Cocco, \& P. Vaz (Orgs.), O trabalho da multidão (pp. 121-146). Rio de Janeiro: Gryphus.

Luiz Alberto Moreira Martins é Psicanalista; Mestre em Psicologia Clínica pela PUC-Rio; Doutorando do programa de Pós-graduação em Psicologia Clínica da PUC-Rio. Email: lammart@globo.com

Carlos Augusto Peixoto Junior é Psicanalista; Doutor em Saúde Coletiva pelo IMS/UERJ; Professor do

Departamento de Psicologia e do Programa de Pós-graduação em Psicologia Clínica da PUC-Rio; Pesquisador do CNPq. Email: cpeixotojr@terra.com.br

\section{Genealogia do Biopoder}

Luiz Alberto Moreira Martins e Carlos Augusto Peixoto Junior

Recebido: 19/03/2008

$1^{\text {a }}$ revisão: $18 / 10 / 2008$

Aceite final: 28/03/2009 